\title{
Research
}

\section{Social Learning and Natural Resource Management: The Emergence of Three Research Perspectives}

\author{
$\underline{\text { Romina Rodela }}^{1}$
}

\begin{abstract}
A review is presented of research contributions that use social learning in research on natural resource management. The review is based on an extensive survey of peer-reviewed journal articles appraised against the following selected analytical items: (1) characterizing features, (2) level of analysis, and (3) operational measures. Together, these allowed for an assessment of underlying assumptions and emerging themes. The findings suggest that, within natural resource management literature, three research approaches to social learning have been developed, each with its own assumptions about the learning process, learning outcomes, and operational practices. Hence, we find that a group of publications showed an interest for participants' learning experiences and focused on the type of outcomes that arise from their attendance in participatory workshops and similar activities. Also, findings indicate that a second group of publications showing an interest for learning in other types of settings, such as groups, networks, and associations, have framed social learning as a process that results in a change in resource management practices, or in how things are done. On the other hand, a third group of publications showed an interest in social-ecological systems emphasizing learning as an emergent property.
\end{abstract}

Key Words: bibliography; natural resource management; social learning; sustainability; systematic review

\section{INTRODUCTION}

Natural systems are complex and dynamic, and there is an intrinsic uncertainty in how ecosystems respond to human interventions (Berkes 2009). This position on natural systems highlights the importance of creating adequate opportunities for flexible, open, and participatory resource management, and it identifies learning-based approaches as a suitable alternative to models used in the past (Armitage 2005, Berkes 2009). This perspective has gained momentum, and over the past years the interest for learning-based approaches has increased. In this, strong is the interest for social learning, a conceptual construct upon which the resource management literature has not reached an agreement. Social learning is conceptualized, understood, and used in many different ways (Muro and Jeffrey 2008, Reed et al. 2010).

The following is a contribution to the on-going discussion about social learning by illustrating the results of a research where the resource management literature was appraised in a systematic way. The purpose of this research was to survey the development of social learning research from the early studies to the most recent ones, paying attention to the aspects that can help future research. The following question guided this process: how is the conceptual construct of social learning defined and used by the resource management literature? To this end, the literature was appraised along three analytical items: (1) characterizing features, (2) level of analysis, and (3) operational measures. The first explores aspects that relate to the learning process and was broken down into two questions: (i) how the literature understands the social learning process, and (ii) what the assumed outcomes of this process are. The second deals with aspects that aim to identify what is being investigated. In this, we shall clarify that a distinction was made between the unit of observation, that is, the level at which data are collected, and the unit of analysis, that is, the level at which conclusions are drawn. In addition, the third explores the issue of how social learning is made operational.

The following section details the methodology. Then, research results are presented and discussed, and in the last section some concluding remarks are given.

\section{METHODS}

The advantages and disadvantages of different appraisal methods to be used for a review of the literature were considered. Keeping in mind that publications on social learning do not use shared research protocols or comparable methodologies, a meta-analysis, which appraises research that uses comparable research designs, was seen as problematic. Alternatively, a systematic review, which allows the evaluation of research that is qualitative and descriptive and that does not use comparable research designs (Petticrew and Roberts 2006), was better suited for this task. Established literature was consulted and the following steps undertaken according to guidelines. First, the inclusion and exclusion criteria used to select the publications were defined. Inclusion criteria chosen for this appraisal were: (i) quality (i.e., publications should be peer-reviewed) and (ii) relevance (i.e., publications should use social learning within the applicative domain of natural resources management). Only one exclusion criterion was used: consistency. Therefore, publications that mentioned the term within the title, abstract, or keywords but did not use it subsequently in the conceptual or empirical part of the study were excluded. Second, for retrieval accuracy, 
two researchers searched electronic bibliographic databases (ISI; SCOPUS). The choice of search terms used followed from the above-stated research question. These were "social learning" and "learning" used both alone and in combination with natural resources, resource systems, and resource management appearing in titles, keywords, or abstracts. It shall be clarified that the focus of this analysis is how selected literature uses a specific term (i.e., social learning) and not the nature of social learning as a concept. For this reason, the inclusion of additional key words that indicate similar or overlapping concepts (e.g., collective learning, capacity building) is beyond the objectives of this study. The date of the last search was November 10, 2010, and publications available after that date are not included here. Retrieved material comprised original articles, reviews, and reflection notes. Third, full papers were checked against the inclusion and exclusion criteria. Fourth, selected publications were appraised, and data were extracted from the papers and put into an Excel spreadsheet for the analysis. Data extraction was performed by the author; it was recorded as text feeding into a qualitative dataset and as numbers (codes) feeding into a quantitative dataset. The present analysis is based mainly on the qualitative dataset.

Data extraction process relied on the above indicated three analytical items; the first one indicating theoretical elements and the other two for methodological choices. The assumption was that the three together could signal for trends and could help to identify similarities and differences in how the term is used. Then a thematic analysis was performed and data approximating similar concepts grouped together. This helped to discriminate between papers, and some trends could be identified. In this, the allocation of selected papers within the three groups was not always straightforward. For instance, in some publications it is assumed that social learning leads to change processes that are of a wider societal relevance but then only data about individuals' learning experiences are analyzed and reported, that is, there is a missing link between the assumptions advanced with the methodology used. In such cases, it was not possible to discriminate on the basis of conceptual and methodological aspects together. Hence, a decision was taken and priority given to aspects of research design and publications falling within the above-mentioned case were allocated in the first group. Review papers are also challenging as these examine the work of others. For reviews, attention was placed on how these position against the term (and not against the literature); for instance, the definition of social learning given by Reed et al. (2010) emphasizes networks and communities of practice, and for this reason, we understood this publication fitting well in the second group. Muro and Jeffey (2008), after examining the literature, unveil their position, stating that social learning is experienced by stakeholders when these come together and because they emphasize the role of participatory workshop, and the implications workshops have for the participants, this publication was seen fitting well in the first group. However, it is recognized that focusing on different aspects, and consequently applying other analytical items, could produce different groups.

It is useful to clarify that the present review is focused on one application domain only, that is, natural resources. Literature that focuses on environmental policy, policy tools, and appraisal methods, and only marginally touches upon natural resource issues, goes beyond the scope of the work reported here. Yet, a comparison of how social learning is used across different disciplinary areas as well as applicative domains is a relevant undertaking of an interest to future research. In the following, results are presented succinctly; given the substantial amount of documents surveyed, citations are kept to a minimum to not compromise readability. The list of selected publications is available in Appendix 1.

Systematic reviews are a useful appraisal method but are not completely immune to criticism. For instance, by focusing on bibliographic databases, some publications, such as books, proceedings, dissertations, and regional non-English journals, are excluded from the review. For an emerging research domain like social learning, this leaves out a substantial number of potentially useful source material. It is not unusual for new ideas and alternative and novel approaches to be presented at conferences and workshops, where comments from an extended peer community are sought in addition to disciplinary-bounded departments, and new ideas or methods are often tested in dissertations and research projects. By focusing on bibliographic databases, this type of material has been excluded. The potential to include material not accessible through these databases was considered, but it was not attempted because we could not identify a systematic way to retrieve it. A second limitation of this research method relates to the appraisal process since it could be influenced by individual subjectivity. To minimize the likelihood of bias, a review protocol, detailing the steps and procedures, and a data extraction form, were used. Test-retest reliability was performed over a two-week interval and was found to be significant.

\section{RESULTS: THREE RESEARCH PERSPECTIVES}

The search resulted in 116 unique publications, of which 97 met the inclusion criteria. Fourteen were excluded because the concept appeared in the publication but was not elaborated upon or used in a concrete way. Five were editorial notes introducing a special issue, and these were also excluded. Several of the selected publications reported on the same study/research project. However, contrary to what some of the methodological literature would suggest about multiple publications, we decided to retain all of them. The aim of this research was to investigate how research uses the term; for 
Table 1. Three research approaches to social learning: main characteristics

\begin{tabular}{|c|c|c|c|}
\hline & Individual-centric & Network-centric & Systems-centric \\
\hline \multicolumn{4}{|c|}{ Characterizing features } \\
\hline Learning process & $\begin{array}{l}\text { Transformative: learning as a } \\
\text { transformative process that occurs during a } \\
\text { participatory activity and involves the } \\
\text { individual }\end{array}$ & $\begin{array}{l}\text { Experiential: learning as a process } \\
\text { embedded in past experience and/or } \\
\text { observation of other practitioners }\end{array}$ & $\begin{array}{l}\text { Emergent: learning as an emergent } \\
\text { property of the social-ecological system }\end{array}$ \\
\hline $\begin{array}{l}\text { Learning } \\
\text { outcomes }\end{array}$ & $\begin{array}{c}\text { A change of participants' internal-reflective } \\
\text { processes; a change of participants' } \\
\text { behavior }\end{array}$ & $\begin{array}{c}\text { A change in established resource use or } \\
\text { management practices }\end{array}$ & $\begin{array}{c}\text { Shift of the social-ecological system on a } \\
\text { more sustainable path }\end{array}$ \\
\hline \multicolumn{4}{|c|}{ Level of analysis } \\
\hline $\begin{array}{l}\text { Unit of } \\
\text { observation }\end{array}$ & The individual & $\begin{array}{c}\text { The individual, network, multi-stakeholder } \\
\text { platform }\end{array}$ & The individual, ecosystems, institutions \\
\hline Unit of analysis & The participant & Networks & The social-ecological system \\
\hline $\begin{array}{l}\text { Learning agent of } \\
\text { interest }\end{array}$ & $\begin{array}{l}\text { The individual who participates in a } \\
\text { participatory workshop }\end{array}$ & $\begin{array}{l}\text { Multi-stakeholder platforms } \\
\text { The practitioner, member of a community } \\
\text { of practice, and/or network of practitioners }\end{array}$ & $\begin{array}{c}\text { The stakeholder, community member, or } \\
\text { practitioner who is involved in resource } \\
\text { management }\end{array}$ \\
\hline \multicolumn{4}{|c|}{ Operationalization } \\
\hline $\begin{array}{l}\text { Operational } \\
\text { measures }\end{array}$ & $\begin{array}{l}\text { Moral dimension (civil virtues), cognitive } \\
\text { dimension (improved understanding of } \\
\text { problem domain), relational dimension } \\
\text { (relational base), trust (trust toward } \\
\text { participants, process) }\end{array}$ & $\begin{array}{c}\text { Change in how things are done; improved } \\
\text { relationships }\end{array}$ & $\begin{array}{l}\text { Change of institutions and management } \\
\text { practices at higher levels (e.g., policy), } \\
\text { with interest for ecosystem responses }\end{array}$ \\
\hline
\end{tabular}

this reason, multiple publications can still contain useful information, and these were included in our reference dataset.

The appraisal of publications against the outlined analytical items allowed for a comparison of how the term is used and suggested that publications can be clustered into three groups (Table 1). Hence, a first group of publications in our reference dataset assumes that social learning is triggered when different stakeholders meet and engage with one another at a participatory workshop, or similar, and occurs when a change is manifested within the cognitive, moral, relational, and trust dimensions of those in attendance at the session. This first group of 16 publications was named individual-centric. The findings indicate that a second group of 53 publications had an interest also in other types of settings, such as groups, networks, and associations, and were focused on changes in practices resulting from practitioners' engagement in such networks. This group was named network-centric. On the other hand, a third group of 28 publications had an interest in social-ecological systems emphasizing learning as an emergent property with implications for the social-ecological system. This group was named systems-centric.

Earlier some had already mentioned that the literature approaches social learning in different ways. For instance,
Armitage et al. (2008:86) distinguish between research that emphasizes learning through partnerships and research that emphasizes "the need to understand individual learning." Also in the response of Reed et al. (2010) to Pahl-Wostl (2006), along with ten other articles published in this journal, different perspectives to social learning are identified. However, since their discussion is based on claims that a shared definition of the construct is needed, differences and similarities between research perspectives are not elaborated in detail. Here, the discussion is taken further by summarizing and highlighting key aspects of the three perspectives as identified by the present research.

\section{An individual-centric perspective \\ Characterizing features}

Therefore, findings indicate that a group of 16 publications share a strong interest in participatory processes and advance the assumption that social learning occurs when stakeholders in the course of a discussion become engaged with one another. It is within this first group of literature that an early attempt to conceptualize social learning in relation to natural resources issues is found. For instance, Webler et al. (1995) bring together participatory democracy (e.g., Barber 1984, Fiorino 1990) with behavioral psychology (e.g., Bandura 1977) in a 
Cooperative Discourse Model applied to an empirical case where citizens took part in a series of participatory workshops (i.e., siting of a landfill). In their research, social learning has been operationalized as moral development and cognitive enhancement that the participants experience and has been used as a criterion to assess the participatory process. Empirical evidence was found for both. With this study, by reaching upon behavioral psychology, Webler et al. (1995) introduce a perspective on participatory resource management, where the emphasis shifts from the outcome to the process itself. Their study highlights process characteristics, the influence this has on the internal-reflective processes of those attending the session, and the transformative change resulting from it. This work has influenced later conceptualizations of social learning and has brought forward expectations about the type of outcomes a social learning process can yield. Based on this work, several research teams have drawn from these insights and similarly have looked at social learning in relation to workshops, or other formally organized settings (e.g., Schusler et al. 2003, Fitzpatrick et al. 2008). However, later research, unlike Webler et al. (1995), does not use social learning as a criterion to assess the participatory process. Instead, it is understood to be the desired outcome in itself and the participatory processes the means to this end.

\section{Level of analysis}

This research found that 15 out of 16 are empirical papers reporting on real world cases and one is a review paper. Publications report on issues of land use, forest management, river basin management, and wildlife management where participatory approaches were used. Publications report about investigations undertaken to gather evidence about the type of change processes participants in participatory processes have experienced. The unit of observation is the individual who took part in participatory activities, and his/her learning experience is investigated with a questionnaire and an interview in order to establish whether learning has occurred and whether it led to the assumed type of change (transformative process). In this, given that publications advance conclusions about social learning that center on the learning process individuals have experienced, we concluded that participants are also the unit of analysis and have clustered publications accordingly.

\section{Operational measures}

The way in which conceptual constructs are made operational has implications on the opportunities for replication and verification of the assumptions. We find that in a sub-group of publications, social learning has been operationalized as a change in one or more dimensions as suggested by Webler et al. (1995); 12 out of 16 publications have operationalized social learning as a process that results in a change in the cognitive, moral, relational, and/or trust dimensions. The assumption these publications share is that the participant, as a result of being involved in a participatory workshop, or other similar activity, learns about the issue under discussion, learns how his/her own interests are linked to those of others, and develops or strengthens relationships. Publications suggest that a change in these dimensions constitutes the basis upon which a transformative process of change involving the individual can unfold.

Additionally, 8 out of 16 publications stated that social learning processes lead to a change in behavior but this was not made operational nor was empirical evidence for such change provided within these publications. Another 6 out of the 16 publications advanced assumptions about social learning and change processes that involve the society at large, but also this was not operationalized nor was empirical evidence provided.

\section{A network-centric perspective Characterizing features}

A second group of 53 publications has focused on activities other than formally organized participatory workshops. Participatory processes are still a recognized and important aspect, but publications are not limited to workshops and expand to include networks of practitioners, user groups, village communities, associations, etc. Compared with participatory workshops, these activities generally include a larger number of participants, cover a longer time frame, and involve those with a specific interest (e.g., farmers, fisherman) rather than the general public. This last aspect is of particular interest to this group of literature. Specifically, these publications focus on the type of group dynamics that is conducive to a change in how things are done. In this sense, we should note that, for this group, the research interest in change processes goes beyond the immediate activity being investigated (e.g., networking) and beyond the internal reflective processes of the individual network member.

A substantial number of publications share the assumption that learning within such networks is rooted in experience and is shared between other members, which makes learning meaningful and embedded within the context of where the learner comes from (e.g., farming, fishing). Similar ideas are found in Wenger's (1999) work on the Communities of Practice (CoP). It is not surprising that 12 out of 53 publications have drawn from Wenger's (1999) research on CoP. Wenger has an interest in applicative domains other than resources management (organizations and management), and he frames social learning in ways that are different from those found in the resource management literature. His influence on the social learning discourse, however, is mediated by those who use his CoP framework. On this point we find it useful to draw on Blackmore's (2010:204) comment, in which she outlines a few differences between the two: "Both Woodhill and Ison are concerned with collective learning and concerted multi-level 
action which they see as essential in their domains of practice, which include development, environmental decision making and natural resource management. In contrast, Etienne Wenger's CoPs-based theory.../... is as much concerned with individual as with collective learning and has been applied, in different ways, in a very wide range of domains. Wenger proposes a social theory of learning rather than a social learning theory. He distinguishes this theory by defining learning as a social and historical process. In considering social learning systems his focus is specifically on CoPs, where effectiveness of these communities depends on the strengths of their structural elements of domain, community and practice."

\section{Level of analysis}

This research found that 44 out of 53 are empirical papers reporting on real-world cases with the exception of two, which discuss an agent-based model. Publications report on cases of land use (3), forest management (11), biodiversity and wildlife (2), river basin management (19), and agriculture (10). Nine papers have a theoretical core or report on lessons learned.

This second group of publications is not locked within learning processes individuals have experienced since publications expand the discussion to include management practices and related activities. For instance, McDaniels and Gregory (2004) report on a multi-stakeholder process in British Columbia (Canada) where they clarify that no formal analysis of learning was conducted and for that reason no conclusions could be offered on this. However, they point to new circumstances that resulted from the process (i.e., resource use and flood control) and see these as evidence upon which claims about multistakeholder processes and social learning could be advanced. Also Schneider et al. (2009) report on change processes that resulted from a multi-actor collaborative activity and describe learning processes that those participating in the activity experienced. Both change processes and learning are used to advance claims about the potential that multi-stakeholder platforms have to foster social learning. It follows that, although the unit of observation is still the individual about whom data is collected, the level of analysis of this second group of publications changes to include higher levels of aggregation, for example, the network, multi-stakeholder platform. It is about the potential these settings have to foster social learning that research falling in this second group has drawn conclusions.

Often, empirical research from this group has reacted upon secondary data in search for evidence. For instance, Brummel et al. (2010) surveyed planning documents in search of evidence about post-activity changes and found that new wildfire management actions were proposed. Frost-Nerbonne and Lentz (2003) integrate qualitative data with newsletters and video material in an investigation of rotational grazing practices and knowledge generation process of a collaborative team. Evidence collected was used to advance claims about the activities being investigated, change processes, and social learning processes.

Operational measures

Of this group, 18 out of 53 publications have framed social learning as a process that results from a change in resource management practices, or in how things are done. Publications have successfully integrated such assumptions in the research design and operational measures used and have reported changes in management practices and resource use patterns. For instance, publications report on activities that led to a change of practices in agriculture (e.g., Frost-Nerbonne and Lentz 2003, Kroma 2006, Ingram 2010), forestry (StandaGunda et al. 2003), and wildlife management (Kendrick and Manseau 2008). Additionally, 12 out of 53 publications have drawn on Wenger's ideas about CoP used directly or indirectly in the operationalization of a social learning framework.

\section{A systems-centric perspective \\ Characterizing features}

This research finds that a third group of 28 publications takes a different approach to social learning compared with the above two groups of publications and has a more explicit focus on social-ecological systems, which are defined as a coupled system of humans and nature. This group of publications supports the assumption that social learning is a process involving system-wide change processes. Hence, the interest is for change that moves the social-ecological system toward a more sustainable trajectory.

Level of analysis

This research found that 22 out of 28 are empirical papers, whereas 6 are theoretical papers or papers where lessons learned are discussed. Also these publications report on realworld cases inclusive of, for example, land use (3), forest management (2), biodiversity and wildlife (2), river basin management (8), and agriculture (2), or report about more of the above (10).

A main difference between this group and the second group of publications is in the way change at higher levels of aggregation is conceptualized. Publications clustered in the second group report on cases where the interest was for change in how things are done. On the other hand, publications clustered in this third group extend this to include environmental responses that follow from human interventions, or change in how things are done. For instance, Rist et al. (2003) investigated a traditional land-use system in the Andes and in this accounted for institutional, historical, religious, and environmental factors. They conclude that, in their study, the land-use system is the result of co-evolution of society and Nature. Olsson et al. (2004:77) define social learning as a collective learning process that "builds 
experience with ecosystem change and evolves as a part of the social memory, and it embeds practices that nurture ecological memory." This process, they continue, is linked to the ability of management to respond to environmental feedback and direct social-ecological systems into sustainable trajectories.

Therefore, publications use more than one unit of observation from which data is collected, for example, wildlife populations, multi-stakeholder platforms, and is used to develop an analysis, with conclusions drawn for the socialecological system under investigation. In this, the role of feedback processes acquires importance and some of the selected publications have described the ecosystem dynamics resulting from human intervention (e.g., Rist et al. 2003, Olsson et al. 2004).

\section{Operational measures}

There are differences, within this third group, in how publications have operationalized social learning; some are interested in institutional change whereas others are interested in environmental responses. Hence, 13 publications out of 28 are focused on actor-oriented processes and operationalize social learning within the elements of institutional change. This research is interested in the ecological properties of the natural resource system, but the core of the discussion is centered on social practices, such as how actors organize, how negotiation occurs, and the institutional implications that arise from this. Questions that touch upon power issues and social capital acquire importance, but policy and its role in facilitating social learning processes is also a recurring theme. For instance, Plummer (2006) has investigated the development of co-management in a Canadian river corridor by analyzing how local actors got organized, the negotiations that followed from this, and the implications that the collaborative activities had on the institutions overseeing the river corridor. On the other hand, 16 publications out of 28 have placed a greater emphasis on the environmental responses to human activities and report upon changes in the ecological system being investigated. This differs from the previous two groups of publications because here the ecological status of the resource system is central, and a description of the ecological aspects is provided. The influence of systems ecology is perceptible in the way this research discusses aspects pertaining to the natural resource ecology, with special attention on scale issues (e.g., Cumming et al. 2006). For instance, Sayles and Mulrennan (2010) have investigated local hunting practices (e.g., mud dykes and cutting of tuuhiikaan) and described the impact these had at the landscape level.

\section{Other trends}

Specific implications can be drawn from the type of assumptions made about the nature of social learning processes. Most publications (81) discussed social learning with regards to interventions, brought from outside the communities, such as participatory workshops, simulation games, community development initiatives, etc. On the other hand, social learning was discussed in relation to processes developed from within the communities, such as farmers' networks (e.g., Frost-Nerbonne and Lentz 2003, Rist et al. 2003) and local management systems (e.g., Olsson et al. 2004, Kendrick and Manseau 2008), in a smaller group of publications (13). However, it is recognized that the type of activity under investigation may not always reflect the assumptions made about the "nature" of social learning processes. Hence, in order to appraise how the literature stands on this aspect, a further step was made by including an item meant to map out whether social learning is understood as an emergent process, which is subject to unpredictability and inclusive of unintended consequences (e.g., failure), or whether it is understood in more deterministic terms of causeeffect dynamics, thereby being linear and predictable. The allocation of publications within one of these two characterizations was performed based on the definitions provided from within the papers. For those publications in which this was not exhaustive, the criteria used to assess social learning, and the statements made about it were considered. Therefore, we found that most publications discussed social learning as a linear process that can be purposefully facilitated (69), whereas others discussed it as an emergent phenomenon (28). This part of the appraisal was the most difficult. Several publications provided loose definitions and did not report on the criteria used for the assessment of social learning, or they did not clarify how the criteria were chosen. Therefore, this result constitutes the weakest part of our appraisal. Yet, the process provided some useful information, for instance, it informed about the practices used, or a lack of these, applied for the assessment of social learning.

\section{DISCUSSION}

The research reported here aimed to gather insight into how social learning is defined and used by the resource management literature. Results indicate that three approaches to social learning have developed, each with its own assumptions of what is meant to change and how this is operationalized. This is consistent with what previous studies have already suggested. For instance, Reed et al. (2010:2) identify literature that "conceptualize social learning as individual learning that takes place in a social context" and other literature that conceptualizes "social learning as a process of social change in which people learn from each other in ways that can benefit wider social-ecological systems." Similarly, Armitage et al. (2008) identify differences between social learning literature and link these differences to the learning theories that scholars borrow from pedagogy and cognate fields, given that some emphasize individual learning and others group learning. This could be extended to our results. Several of the above-illustrated differences between groups of literature could be explained against theories that 
scholars have brought together. As already indicated, the influence of participatory democracy on the first group of literature, the influence of Wenger's (1999) CoP on the second group, and the influence of ecology and soft system thinking on the third group of publications can be seen in the assumptions publications advance about what is meant to change and in the operationalizations used. However, a detailed deconstruction of how interdisciplinary engagement contributes to shape social learning research is beyond the objectives of this discussion.

In their analysis of social learning literature, Reed et al. (2010) identify the need to distinguish between the conditions or methods that facilitate social learning and the potential outcomes of a social learning process. We share this position and a focus on aspects of research design helped to map out what the literature says about the methods to facilitate social learning and the outcomes. Hence, this study finds that most publications discuss social learning with regards to interventions as are, for example, workshops, multistakeholder platforms. Indeed interventions constitute a fertile ground for exploratory research since, with a suitable research design, effects could be appraised and assumptions verified. However, only a few have chosen to do so. Moreover, in several cases, the appraisal of social learning falls behind other objectives as, for instance, the evaluation of the participatory process, which is a legitimate choice, but on the other hand raises questions about the suitability of such an appraisal method for advancing claims about social learning. In this, when the method used was meant to evaluate other processes, a need emerges to justify how this contributes to understanding social learning, in particular when aspects meant to look at social learning are not included in the research design.

On the other hand, a focus on interventions brings up specific assumptions about the nature of social learning processes. For instance, in several publications, interventions, such as participatory workshops, are discussed as being the tools to trigger social learning, and in some cases, interventions were described without further elaboration upon the contextual aspects that may have an influence. In this sense, when publications discuss social learning in terms of a cause-effect dynamic, a tension may be identified with the rationale that led to social learning research in the first place. Much of the social learning research frames an explicit critique of the reductionist rationale, which in resource management resulted in technical end-of-pipe solutions (Pahl-Wostl 2002). This critique recognizes the role of social and institutional aspects, complexity, and uncertainty, which characterize environmental issues. However, some publications report on interventions which led, or should have led, to social learning with little or no discussion of the contextual elements involved. This tension, we assume, could be understood against the undernourished theoretical agenda that currently characterizes the discourse.
At this point, having outlined some trends and highlighted aspects that are seen to characterize the discourse along three research approaches, a legitimate question may arise: how generative is that research with an interest in social learning, as an alternative approach for coping with current resource challenges, is pursuing different research agendas? Reflecting on this examination, it is useful to postulate that the type of change process of interest to this literature is difficult to theorize. Large-scale phenomena, such as the transition to a more sustainable world/path/future, which seems to be of interest in many publications, involves the convergence of a number of different processes, some of which may be linked, whereas others act independently. In this sense, the process comprises behaviors, practices, and institutions, but also different levels of aggregation (e.g., individuals, communities, regions, ecosystems), and this makes it a difficult process to theorize. As stated by Geddes (2003), in principle, a multifaceted theory could explain large-scale phenomena; however, in doing so, valuable detail is lost. Her suggestion for an effective accumulation of theoretical knowledge is to focus on individual processes that contribute to the final outcome, with the goal of generating testable propositions. It follows from this standpoint that more than one research agenda could also have some advantages. Nevertheless, social learning research is in its initial stage, and as interest in these alternative approaches develops, many aspects will need to be negotiated, agreed upon, and theorized.

\section{CONCLUSIONS}

Recently, interest in social learning as an alternative approach to natural resource management has increased substantially, and the discourse is characterized by a substantial body of literature that does not seem to agree on exactly what this conceptual construct entails. Social learning is conceptualized, understood, and used in many different ways, thereby resulting in some criticism. However, this review suggests that research shares several features and can be clustered into three groups, or research perspectives, each with its own assumptions about the learning process, learning outcomes, and operational practices. Hence, publications that are identified as taking an individual-centric approach suggest that social learning is triggered when different stakeholders meet and engage with one another at a participatory workshop, or similar activity, and occurs when a change is manifested within the cognitive, moral, relational, and trust dimensions of those in attendance at the session. Publications that are identified as taking a network-centric approach extend this to include other activities, such as forums or other type of collaborative meetings, and suggest that social learning is triggered when practitioners and members of a network or an association engage with one another and share their experiences and knowledge. These studies recognize the role of a participatory process but are not limited to it. These publications discuss social learning in relation to a change in how things are done 
(e.g., management practices). Conversely, those publications that are identified as having a systems-centric approach discuss social learning as a change process that moves the social-ecological system on a more sustainable trajectory. This literature touches aspects of governance and structural change but also provides a description of the resource system and ecological status and considers the environmental responses to human interventions.

Building on this analysis, we propose that if social learning research is to progress, then future studies should build upon both the theoretical and the empirical agendas. Future research could contribute to the theoretical agenda by addressing ontological and epistemological aspects. If social learning is to be understood as involving a process of change, then the field would benefit from further reflection about the following: What is meant to change? What could be considered as a proof of change? Who defines the direction of such change? What means could help to this end? Second, research could explore research methodologies that allow for a suitable integration, and validation, of the assumptions advanced and also could explore the criteria that can best help in the assessment of social learning processes.

Responses to this article can be read online at: http://www.ecologyandsociety.org/voll6/iss4/art30/ responses/

\section{Acknowledgments:}

This research was funded under the FP7-PEOPLE-Marie Cure-Action IEF and is part of the project titled Social Learning Processes in Natural Resource Management. The author would like to thank Eliana Alba Alba for help with the bibliographic search and Georgina Cundill for comments on an earlier draft.

\section{LITERATURE CITED}

Armitage, D. 2005. Adaptive capacity and community-based natural resource management. Environmental Management 35:703-715.

Armitage, D., M. Marschke, and R. Plummer. 2008. Adaptive co-management and the paradox of learning. Global Environmental Change 18:86-98.

Bandura, A. 1977. Social learning theory. Prentice-Hall International, London, UK.

Barber, B. 1984. Strong democracy: participatory politics for a new age. University of California Press, Berkeley, California, USA.

Berkes, F. 2009. Evolution of co-management: role of knowledge generation, bridging organizations and social learning. Journal of Environmental Management 90:1692-1702.
Blackmore, C. 2010. Social learning systems and communities of practice. Springer-Verlag London, UK.

Brummel, R. F., K. C. Nelson, S. G. Souter, P. J. Jakes, and D. R. Williams. 2010. Social learning in a policy-mandated collaboration. Journal of Environmental Planning and Management 53:681-699.

Cumming, G. S., D. H. M. Cumming, and C. L. Redman. 2006. Scale mismatches in social-ecological systems: causes, consequences, and solutions. Ecology and Society 11(1): 14. [online] URL: http://www.ecologyandsociety.org/vol11/iss1/ $\underline{\operatorname{art} 14 /}$

Fiorino, D. J. 1990. Citizen participation and environmental risk: a survey of institutional mechanisms. Science, Technology and Human Values 15:226-243.

Fitzpatrick, P., A. J. Sinclair, and B. Mitchell. 2008. Environmental impact assessment under the Mackenzie Valley Resource Management Act: deliberative democracy in Canada's North? Environmental Management 42:1-18.

Frost-Nerbonne, J., and R. Lentz. 2003. Rooted in grass: challenging patterns of knowledge exchange as a means of fostering social change in a southeast Minnesota farm community. Agriculture and Human Values 20:65-78.

Geddes, B. 2003. Paradigms and sand castles: theory building and research design in comparative politics. University of Michigan Press, Ann Arbor, Michigan, USA.

Ingram, J. 2010. Technical and social dimensions of farmer learning. Journal of Sustainable Agriculture 34:183-201.

Kendrick, A., and M. Manseau. 2008. Representing traditional knowledge: resource management and inuit knowledge of barren-ground caribou. Society \& Natural Resources 21:404-418.

Kroma, M. M. 2006. Organic Farmer Networks: facilitating learning and innovation for sustainable agriculture. Journal of Sustainable Agriculture 28:5-28.

McDaniels, T. L., and R. Gregory. 2004. Learning as an objective within a structured risk management decision process. Environmental Science \& Technology 38:1921-1926.

Muro, M., and P. Jeffrey. 2008. A critical review of the theory and application of social learning in participatory natural resource management processes. Journal of Environmental Planning and Management 51:325-344.

Olsson, P., C. Folke, and F. Berkes. 2004. Adaptive comanagement for building resilience in social-ecological systems. Environmental Management 34:75-90.

Pahl-Wostl, C. 2002. Towards sustainability in the water sector: the importance of human actors and processes of social learning. Aquatic Sciences 64:394-411. 
Pahl-Wostl, C. 2006. The importance of social learning in restoring the multifunctionality of rivers and floodplains. Ecology and Society 11(1): 10. [online] URL: http://www.eco logyandsociety.org/vol11/iss1/art10/

Petticrew, M., and H. Roberts. 2006. Systematic reviews in the social sciences: a practical guide. Blackwell Malden, Malden, Massachusetts, USA.

Plummer, R. 2006. Sharing the management of a river corridor: a case study of the comanagement process. Society and Natural Resources 19:709-721.

Reed, M. S., A. C. Evely, G. Cundill, I. Fazey, J. Glass, A. Laing, J. Newig, B. Parrish, C. Prell, C. Raymond, and L. C. Stringer. 2010. What is social learning? Ecology and Society 15(4): r1. [online] URL: http://www.ecologyandsociety.org/vol15/ iss $4 / \mathrm{resp} 1 /$

Rist, S., F. Delgado, and U. Wiesmann. 2003. The role of social learning processes in the emergence and development of aymara land use systems. Mountain Research and Development 23:263-270.

Sayles, J. S. , and M. E. Mulrennan. 2010. Securing a future: cree hunters' resistance and flexibility to environmental changes, Wemindji, James Bay. Ecology and Society 15(4): 22. [online] URL: http://www.ecologyandsociety.org/vol15/iss4/ art22/

Schneider, F., P. Fry, T. Ledermann, and S. Rist. 2009. Social learning processes in Swiss soil protection: the "From Farmerto-Farmer" project. Human Ecology 37:475-489.

Schusler, M. T., J. D. Decker, and J. M. Pfeffer. 2003. Social learning for collaborative natural resource management. Society and Natural Resources 15:309-326.

Standa-Gunda, W., T. Mutimukuru, R. Nyirenda, R. Prabhu, M. Haggith, and J. Vanclay. 2003. Participatory modelling to enhance social learning, collective action and mobilization among users of the mafungautsi forest, Zimbabwe. SmallScale Forestry 2:313-326.

Webler, T., H. Kastenholz, and O. Renn. 1995. Public participation in impact assessment: a social learning perspective. Environmental Impact Assessment Review 15:443-463.

Wenger, E. 1999. Communities of practice: learning, meaning, and identity. Cambridge University Press, Cambridge, UK. 


\section{Appendix 1. List of selected publications}

No. Author(s) - year - title - journal

First group

1 BLACKSTOCK et al, 2009. Climate proofing Scottish river basin planning - a future challenge. Environmental Policy and Governance, 1966):374-387.

2 CHENG and MATTOR, 2010. Place-Based Planning as a Platform for Social Learning: Insights From a National Forest Landscape Assessment Process in Western Colorado. Society \& Natural Resources: An International Journal, 23(5):385 - 400.

3 DURCOT, 2009 Gaming across scale in peri-urban water management: Contribution from two experiences in Bolivia and Brazil International Journal of Sustainable Development and World Ecology, 16 (4): $240-252$

4 FITZPATRICK, SINCLAIR and MITCHELL, 2008. Environmental impact assessment under the Mackenzie Valley Resource Management Act: Deliberative democracy in Canada's North? Environmental Management, $42(1): 1-18$.

5 LEYS and VANCLAY, 2010. Stakeholder engagement in social learning to resolve controversies over land-use change to plantation forestry. Regional Environmental Change , 1-16.

$6 \mathrm{Mc}$ CRUMet al., 2009. Adapting to climate change in land management: the role of deliberative workshops in enhancing social learning. Environmental Policy and Governance, 19(6):413-426.

7 GARMENDIA and STAGL,2010. Public participation for sustainability and social learning: concepts and lessons from three case studies in Europe. Ecological Economics, 69:1712-1722.

8 MURO and JEFFEY, 2008. A critical review of the theory and application of social learning in participatory natural resource management processes. Journal of Environmental Planning and Management, $51(3): 325$ - 344.

9 PAHL-WOSTL and HARE, 2004. Processes of Social Learning in Integrated Resources Management. Journal of Community \& Applied Social Psychology, 14:193-206.

10 RIST et al., 2006.The Multidimensionality of Social Learning Processes Concerned with Sustainable Natural Resource Use in India, Africa and Latin America. Systemic Practice and Action Research, 19(3):219-237.

11 SAARIKOSKI, 2000. Environmental Impact Assessment as a Collaborative Learning Process. Environmental Impact Assessment Review, 20:681-700.

12 SCHUSLER, DECKER and PFEFFER, 2003. Social Learning for Collaborative Natural Resource Management. Society and Natural Resources, 15:309-326.

13 SELIN et al., 2007. Social learning and building trust through a participatory design for natural resource planning. Journal of Forestry, 105(8):421-425.

14 SINCLAIR and DIDUCK, 2001. Public involvement in EA in Canada: a transformative learning perspective. Environmental Impact Assessment Review, 21:113-136.

15 WEBLER, KASTENHOLZ and RENN, 1995. Public participation in impact assessment: A social learning perspective. Environmental Impact Assessment Review, 15(5):443-463.

16 ZANETELL, 2001. Legislating community-based management: Lessons from the Venezuelan freshwater fishery Journal of International Wildlife. Law and Policy, 4 (3): $279-294$.

Second group

17 ANDREW, 2003. Key features of the regional producer network for enabling social learning. Australian Journal of Experimental Agriculture, 43(7-8):1015-1029.

18 BLACKMORE, 2007. What kinds of knowledge, knowing and learning are required for addressing resource dilemmas?: a theoretical overview. Environmental Science \& Policy, 10(6):512-525.

19 BLATNER et al., 2001. Evaluating the application of collaborative learning to the Wenatchee fire recovery planning effort. Environmental Impact Assessment Review, 21:241-270.

20 BLOM-ZANDSTRA and Van KEULEN,2008. Innovative concepts towards sustainability in organic horticulture: testing a participatory technology design. International Journal of Agricultural Sustainability, 6:195-207.

21 BOROWSKI and PAHL-WOSTL, 2008. Where can social learning be improved in international river basin management in Europe? European Environment, 18, 216-227.

22 BOROWSKI, 2010. Social Learning Beyond Multi-stakeholder Platforms: A Case Study on the Elbe River Basin. Society \& Natural Resources: An International Journal, 23(10):1002-1012.

23 BOUWEN and TAILLEU, 2004. Multi-party collaboration as social learning for interdependence. Journal of Community \& Applied Social Psychology, 14(3):137-153.

24 BROWN, BUCK and LASSOIE, 2008. Governance and social learning in the management of Non-Wood Forest Products in community forests in Cameroon. International Journal of Agricultural Resources, Governance and Ecology, 7(3):256-275.

25 BRUMMEL et al., 2010. Social learning in a policy-mandated collaboration. Journal of Environmental Planning and Management, 53(6):681-699

26 COLINS and ISON 2009. Social Learning as a New Policy Paradigm for Climate Change Adaptation. Env. Pol. Gov. 19, 358-373.

27 CoLLINS et al., 2007. A systemic approach to managing multiple perspectives and stakeholding in water catchments: some findings from three UK case studies. Environmental Science \& Policy, 10, 564-574.

28 DANIELL et al 2010. Co-engineering Participatory Water Management Processes. Ecology and Society, 15(4):11.

29 DANIELS and WALKER, 1996. Collaborative Learning: Improving Public Deliberation in Ecosystem-based Management. Environmental Impact Assessment Review, 16:71-102.

30 DAVIDSON-HUNT, 2006. Adaptive learning networks: Developing resource management knowledge through social learning forums. Human Ecology, 34(4):593-614

31 DEDEURWAERDERE, 2009. Social Learning as a Basis for Cooperative Small-Scale Forest Management. Small-Scale Forestry, 8(2):193-209.

32 ELBAKIDZE et al,2010. Multi-Stakeholder Collaboration in Russian and Swedish Model Forest Initiatives: Adaptive Governance Toward Sustainable Forest Management? Ecology and Society, 15(2).

33 FERNANDEZ-GIMENEZ, BALLARD and STURTEVANT, 2008. Adaptive management and social learning in collaborative and community-based monitoring. Ecology and Society, 13(2).

34 FROST et al, 2006. Landscape-scale approaches for integrated natural resource management in tropical forest landscapes. Ecology and Society, 11(2):30.

35 GOOCH and RIGANO, 2010. Enhancing Community-scale Social Resilience: what is the connection between healthy communities and ealthy waterways? Australian Geographer, 41(4):507-520. 
36 HERMANS et al,, 2007. Collaborative environmental planning in river management int. Journal of Environmental Management, 84(4):534-546.

37 INGRAM, 2010. Technical and Social Dimensions of Farmer Learning: An Analysis of the Emergence of Reduced Tillage Systems in England. Journal of Sustainable Agriculture, 34(2):183-201.

38 ISON and WATSON,2007. Illuminating the Possibilities for Social Learning in the Management of Scotland's Water. Ecology and Society, 12(1)

39 JIGGINS, Van SLOBBE and RöLING, 2007. The organisation of social learning in response to perceptions of crisis in the water sector of The Netherlands. Environmental Science \& Policy, 10(6):526-536.

40 KEEN and MAHANTY, 2006. Learning in Sustainable Natural Resource Management: Challenges and Opportunities in the Pacific. Society \& Natural Resources: An International Journal, 19(6):497-513.

41 KENDRICK and MANSEAU, 2008. Representing Traditional Knowledge: Resource Management and Inuit Knowledge of Barren-Ground Caribou. Society \& Natural Resources: An International Journal, $21(5): 404$ - 418.

42 KROMA, 2003. Participation and social leanring: farmer inno Gana.J. of unternational agriculture and extension education, 10(1).

43 KROMA, 2006. Organic Farmer Networks: Facilitating Learning and Innovation for Sustainable Agriculture. Journal of Sustainable Agriculture, 28(4):5 - 28

44 KUMLER and LEMOS, 2008. Managing Waters of the Paraiba do Sul River Basin, Brazil: a Case Study in Institutional Change and Social Learning. Ecology and Society 13 (2).

45 KUPER et al., 2009. Supporting the Shift from State Water to Community Water. Ecology and Society, 14(1).

46 LOMBARD et al, 2010. Designing Conservation Corridors in Production Landscapes: Assessment Methods, Implementation Issues, and Lessons Learned Ecology and Society, 15(3):7,

47 MAHANTY et al., 2007. Learning to learn: Designing monitoring plans in the Pacific Islands International Waters Project. Ocean and Coastal Management, 50(5-6):392-410.

48 MAUREL et al. 2007. Concepts and methods for analysing the role of information and Communication tools (IC-tools) in Social Learning processes for River Basin Management. Environmental Modelling \& Software, 22: 630-639.

49 MCDANIELS and GREGORY, 2004. Learning as an Objective within a Structured Risk Management Decision Process. Environmental Science \& Technology, 38, $1921-1926$.

50 MCLAIN and LEE, 1996. Adaptive management: Promises and pitfalls. Environmental Management, 20(4):437-448.

51 MEASHAM, 2009. Social learning through evaluation: A case study of overcoming constraints for management of dryland salinity. Environmental Management, 43(6):1096-1107.

52 MEASHAM, KELLY and SMITH, 2007. Best Management Practice for Complex Problems: a Case Study of Defining BMP for Dryland Salinity. Geographical Research, 45(3):262-272.

53 MILAR and CURTIS, 1999. Challenging the boundaries of local and scientific knowledge in Australia: Opportunities for social learning in managing temperate upland pastures. Agriculture and Human Values, 16(4):389-399.

54 MOSTERT et al., 2007 Social learning in European river basin management: Barriers and fostering mechanisms from 10 river basins'. Ecology and Society, 12(1).

55 FROST-NERBONNE and LENTZ, 2003. Rooted in grass: Challenging patterns of knowledge exchange as a means of fostering social change in a southeast Minnesota farm community. Agriculture and Human Values, 20(1):65-78.

56 PAHL-WOSTL et al., 2007. Social Learning and Water Resources Management. Ecology and Society, 12(2):10.

57 PAHL-WOSTL et al, 2008. The importance of social learning and culture for sustainable water management. Ecological Economics, 64: 484-495.

58 PAHL-WOSTL, 2002. Towards sustainability in the water sector - The importance of human actors and processes of social learning. Aquatic Sciences - Research Across Boundaries, 64, 394-411.

59 PAHL-WOSTL, 2006. The Importance of Social Learning in Restoring the Multifunctionality of Rivers and Floodplains. Ecology and Society, 11(1):10.

60 PAHL-WOSTL, 2007. The implications of complexity for integrated resources management. Environmental Modelling \& Software, 22, 561-569.

61 PRELL et al., 2009. 'Who's in the network?' When stakeholders influence data analysis Systemic Practice and Action Research, 21:443-458.

62 REED et al, 2010. What is Social Learning? Ecology and Society, 15(4).

63 RODRIGUEZ and VERGARA-TENORIO, 2007. Reflections on the social learning process for community work in rural areas of Mexico. International J Journal of Biodiversity Science \& Management, 3(1):31 - 45.

64 SATAKE A. et al. (2007a) Synchronized deforestation induced by social learning under uncertainty of forest-use value. Ecol Econ 63:452-467

65 SATAKE A. et al. (2008) Comparison between perfect information and passive-adaptive social learning models of forest harvesting Theor Ecol, 1:189-197.

66 SCHNEIDER et al., 2009. Social Learning Processes in Swiss Soil Protection: The 'From Farmer - To Farmer' Project. Human Ecology, 37(4):475-489.

67 STANDA-GUNDA et al., 2003. Participatory modeling to enhance social learning Zimbabwe. Small-Scale Forestry, 2(2):313-326

68 TODERI et al., 2007. Combining social learning with agro-ecological research practice for more effective management of nitrate pollution. Environmental Science \& Policy, 10(6):551-563.

69 UMEMOTO and SURYANATA, 2006 Technology, Culture, and Environmental Uncertainty: Considering Social Contracts in Adaptive Management Journal of Planning Education and Research, 25:264-274

\section{Third group}

70 ARMITAGE et al., 2009. Adaptive co-management for social-ecological complexity. Frontiers in Ecology and the Environment, 7(2):95-102.

71 ARMITAGE, 2005. Community-Based Narwhal Management in Nunavut, Canada: Change, Uncertainty, and Adaptation. Society \& Natural Resources: An International Journal, 18(8):715-731.

72 ARMITAGE, MARSCHKE and PLUMMER, 2008. Adaptive co-management and the paradox of learning. Global Environmental Change, 18:86-98.

73 BERKES, 2009. Evolution of co-management: Role of knowledge generation, bridging organizations and social learning. Journal of Environmental Management, 90(5):1692-1702.

74 BOMMEL et al., 2009. Social learning for solving complex problems: a promising solution or wishful thinking? Environmental Policy and Governance, 19(6):400-412.

75 CAMPBELL et al, 2006. What Kind of Research and Development is Needed for Natural Resource Management? Water International, 31(3):343 - 360.

76 CUMMING,CUMMING,and REDMAN, 2006. Scale mismatches in social-ecological systems: Causes, consequences, and solutions. Ecology and Society, 11(1). 
77 CUNDILL and FABRICIUS, 2009. Monitoring in adaptive co-management: Toward a learning based approach. Journal of Environmental Management, 90(11):3205-3211.

78 CUNDILL, G., 2010. Monitoring social learning processes in adaptive comanagement: Three case studies from South Africa. Ecology and Society, 15(3).

79 FENNELL, PLUMMER and MARSCHKE, 2008. Is adaptive co-management ethical? Journal of Environmental Management, 88(1):62-75.

80 ISON, RÖLING, and WATSON, 2007. Challenges to science and society in the sustainable management and use of water: investigating the role of social learning. Environmental Science and Policy, 10(6):499-511.

81 LEBEL, GROTHMANN, and SIEBENHÜNER, 2010. The role of social learning in adaptiveness: insights from water management. International Environmental Agreements: Politics, Law and Economics, 10(4):333-353.

82 MAARLEVELD and DABGBÉGNON, 1999. Managing natural resources: A social learning perspective. Agriculture and Human Values, 16:267-280

83 OLSSON, FOLKE, and BERKES, 2004. Adaptive Comanagement for Building Resilience in Social-Ecological Systems. Environmental Management, $34(1): 75$ - 90.

84 PLUMMER, 2006. Sharing the Management of a River Corridor: A Case Study of the Comanagement Process. Society \& Natural Resources, 19(8):709-721.

85 RIST, DELGRADO and WIESMANN, 2003. The role of social learning processes in the emergence and development of Aymara land use systems. Mountain Research and Development, 23(33), 263-270.

86 RöLNG, N., 2003. From Causes to Reasons: The Human Dimension of Agricultural Sustainability. International Journal of Agricultural Sustainability, $11(1$.

87 SANGINGA, KAMUGISHA and MARTIN, 2010. Strengthening Social Capital for Adaptive Governance of Natural Resources: Reforms in Uganda. Society \& Natural Resources: An International Journal, 23(8):695 - 710.

88 SAYLES and MULRENNAN, 2010. Securing a Future: Cree Hunters' Resistance and Flexibility to Environmental Changes, Wemindji, James Bay. Ecology and Society, 15(4):22.

89 SHACKLETON, CUNDILL, and KNIGHT, 2009. Beyond Just Research: Experiences from Southern Africa in Developing Social Learning Partnerships for Resource Conservation Initiatives. Biotropica, 41(5):563-570.

90 STANKEY, CLARK and BORMANN, 2005. Adaptive management of natural resources: Theory, concepts, and management institutions. USDA Forest Service - General Technical Report PNW, (654):1-73.

91 STEYAERT et al, 2007. The role of knowledge and research in facilitating social learning among stakeholders in natural resources management in the French Atlantic coastal wetlands. Environmental Science \& Policy, 10(6):537-550.

92 STEYAERT and JIGGINS, 2007. Governance of complex environmental situations through social learning: a synthesis of SLM's lessons for research, policy and practice. Environmental Science \& Policy, 10(6):575-586.

93 TABARA and PAHL-WOSTL, 2007. Sustainability learning in natural resource use and management. Ecology and Society, 12(2).

94 TIPPETT et al., 2005. Social learning in public participation in river basin management-early findings from HarmonicoP European case studies. Environmental Science \& Policy, 8(3):287-299.

95 TODT, MUÑOZ and PLAZA, 2007. Food safety governance and social learning: The Spanish experience. Food Control, 18(7):834-841.

96 TOMPKINS and ADGER, 2004. Does adaptive management of natural resources enhance resilience to climate change? Ecology and Society, 9(2).

97 WOLLENBERG, 2001. Social learning in community forests, CIFOR, Bogor. 